This item was submitted to Loughborough's Research Repository by the author.

Items in Figshare are protected by copyright, with all rights reserved, unless otherwise indicated.

\title{
The physiological strain index does not reliably identify individuals at risk of reaching a thermal tolerance limit
}

\section{PLEASE CITE THE PUBLISHED VERSION}

https://doi.org/10.1007/s00421-021-04642-3

\section{PUBLISHER}

Springer Science and Business Media LLC

\section{VERSION}

VoR (Version of Record)

\section{PUBLISHER STATEMENT}

This is an Open Access Article. It is published by Springer under the Creative Commons Attribution 4.0 Unported Licence (CC BY). Full details of this licence are available at: http://creativecommons.org/licenses/by/4.0/

\section{LICENCE}

CC BY 4.0

\section{REPOSITORY RECORD}

Davey, Sarah, Victoria Downie, Katy Griggs, and George Havenith. 2021. "The Physiological Strain Index Does Not Reliably Identify Individuals at Risk of Reaching a Thermal Tolerance Limit”. Loughborough University. https://hdl.handle.net/2134/14178443.v1. 


\title{
The physiological strain index does not reliably identify individuals at risk of reaching a thermal tolerance limit
}

\author{
Sarah L. Davey ${ }^{1,2} \cdot$ Victoria Downie $^{1,3} \cdot$ Katy Griggs ${ }^{1,4} \cdot$ George Havenith $^{1}$ (D)
}

Received: 10 July 2020 / Accepted: 13 February 2021 / Published online: 7 March 2021

(c) The Author(s) 2021

\begin{abstract}
Purpose The physiological strain index (PSI) was developed to assess individuals' heat strain, yet evidence supporting its use to identify individuals at potential risk of reaching a thermal tolerance limit (TTL) is limited. The aim of this study was to assess whether PSI can identify individuals at risk of reaching a TTL.

Methods Fifteen females and 21 males undertook a total of 136 trials, each consisting of two 40-60 minute periods of treadmill walking separated by $\sim 15$ minutes rest, wearing permeable or impermeable clothing, in a range of climatic conditions. Heart rate (HR), skin temperature $\left(T_{\mathrm{sk}}\right)$, rectal temperature $\left(T_{\mathrm{re}}\right)$, temperature sensation (TS) and thermal comfort (TC) were measured throughout. Various forms of the PSI-index were assessed including the original PSI, PSI fixed $_{\text {, adaptive-PSI }}$ (aPSI) and a version comprised of a measure of heat storage $\left(\mathrm{PSI}_{\mathrm{HS}}\right)$. Final physiological and PSI values and their rate of change (ROC) over a trial and in the last 10 minutes of a trial were compared between trials completed (C, 101 trials) and those terminated prematurely (TTL, 35 trials).

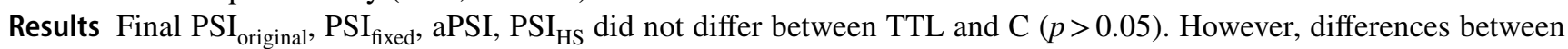
TTL and C occurred in final $T_{\mathrm{sk}}, T_{\mathrm{re}}-T_{\mathrm{sk}}$, TS, TC and ROC in PSI $\mathrm{Pixed}_{\text {fix }}, T_{\mathrm{re}}, T_{\mathrm{sk}}$ and HR $(p<0.05)$.

Conclusion These results suggest the PSI, in the various forms, does not reliably identify individuals at imminent risk of reaching their TTL and its validity as a physiological safety index is therefore questionable. However, a physiologicalperceptual strain index may provide a more valid measure.
\end{abstract}

Keywords Physiological strain index · Heat stress · Heat stress indices · Thermal tolerance limit · Heat illness · Hyperthermia-induced fatigue

Abbreviations

HIF Hyperthermia-induced fatigue

TTL Thermal tolerance limit PSI fixed

PSI Physiological strain index

Communicated by Narihiko Kondo.

George Havenith

G.Haventh@lboro.ac.uk

1 Environmental Ergonomics Research Centre,

Loughborough Design School, Loughborough University,

Loughborough LE11 3TU, UK

2 Department of Health and Life Sciences, Coventry University, Oxford, UK

3 English Institute of Sport, Manchester, UK

4 Department of Engineering, School of Science and Technology, Nottingham Trent University, Nottingham, UK
PSI $_{\text {original }}$ The physiological strain index calculated from actual resting values

$\mathrm{PSI}_{\text {fixed }} \quad$ The physiological strain index calculated from fixed resting values i.e. $37.0^{\circ} \mathrm{C}$ and 70 b $\min ^{-1}$

aPSI The adaptive physiological strain index

PSI $_{\mathrm{HS}} \quad$ The physiological strain index calculated from an estimate of heat storage

$T_{\mathrm{c}}$

$T_{\mathrm{sk}}$

$T_{\text {re }}$

$T_{\mathrm{re}}-T_{\mathrm{sk}}$

$T_{\text {re10 }}$

$T_{\text {sk10, }}$

$\mathrm{HR}_{10}$

Skin temperature

Rectal temperature

The gradient between $T_{\text {re }}$ and $T_{\text {sk }}$

Rate of change in rectal temperature over the last 10 minutes of a trial

Rate of change in skin temperature over the last 10 minutes of a trial

Rate of change in heart rate over the last 10 min of a trial 


$\begin{array}{ll}T_{\text {re10 }}-T_{\text {sk10 }} & \begin{array}{l}\text { Rate of change in the gradient between } T_{\text {re }} \\ \text { and } T_{\text {sk }} \text { over the last } 10 \text { minutes of a trial }\end{array} \\ \text { PSI }_{\text {fixed10 }} & \begin{array}{l}\text { Rate of change in PSI } \\ \text { fixed }\end{array} \text { over the last } \\ \text { HR } & \begin{array}{l}\text { Heart rate of a trial } \\ \text { PPE }\end{array} \\ \text { TC } & \text { Personal protective equipment } \\ \text { TS } & \text { Termal comfort } \\ \text { ROC } & \text { Rate of change } \\ \dot{V} O_{2 \text { peak }} & \text { Peak oxygen uptake }\end{array}$

\section{Introduction}

Heat stress experienced within the workplace can result in hyperthermia-induced fatigue (Nybo et al. 2014), which, left untreated or not identified early, can develop into more serious heat-related illnesses such as heat exhaustion, heat syncope, or in extreme cases heat stroke and death (Arbury et al. 2014). Hyperthermia-induced fatigue (HIF) as well as heat-related illnesses (both of which can be considered to cause an individual to reach a thermal tolerance limit) are of a major concern for industries as they can lead to accidents, absenteeism and can negatively affect the health and safety of their workers (Flouris et al. 2018; Seppänen and Fisk 2005). It can also lead to a reduction in work productivity (Flouris et al. 2018; Foster et al. 2019); an issue detrimental to any industry.

Workers who are required to wear personal protective equipment (PPE) or, due to working outdoors, are exposed to high levels of heat, humidity and/or solar radiation are considered to be most at risk of HIF and heat-related illnesses (ILO 2016; Schulte et al. 2016). To combat this issue, several heat strain indices or monitoring tools have been developed to inform occupational heat stress standards or guidelines (Havenith and Fiala 2015). These guidelines generally provide recommended heat exposure limits based on environmental (e.g. ambient temperature, relative humidity, wind speed, clothing insulation) or physiological (core temperature, heart rate, skin temperature) parameters, or a combination of both, to ensure that the group's average core temperature $\left(T_{\mathrm{c}}\right)$ does not exceed $38.0{ }^{\circ} \mathrm{C}$ (ACGIH 2009; Jendritzky et al. 2012; National Institute for Occupational Safety and Health [NIOSH] 2016; ISO 2004; Malchaire et al. 2001). The main criticism of these indices, however, is that they are based on average group responses, are therefore conservative, and not appropriate to measure detrimental levels of heat stress at an individual level.

The physiological strain index (PSI) was developed to reduce incidences of heat-related illnesses at an individual level (Moran et al. 1998b). Unlike the predictive standards mentioned above, the PSI is a 'live' monitoring tool and is calculated using measures of rectal temperature $\left(T_{\text {re }}\right)$ and heart rate (HR) to reflect the combined strain of the cardiovascular and thermoregulatory systems; with both parameters contributing equally in evaluating physiological strain. Physiological strain is described on a universal scale of 0-10 and is used to classify individuals into certain risk categories, with 0 representing no physiological strain, 10 representing highest physiological strain and $\geq 7.5$ being considered as high risk for thermal injury (Buller et al. 2008; Moran et al. 1998b). While PSI was in part developed as a heat illness prevention tool, it has mainly been validated regarding its ability to distinguish between different levels of thermal strain in different heat stress scenarios including both hot-dry and hot-wet environments, differing hydration levels, impact of differing PPE and between the sexes (Moran et al. 1998a, 1999; Moran 2000; Petruzzello et al. 2009). These validation studies confirm the close relationship between environmental heat stress and the cardiovascular (i.e. heart rate) and thermoregulatory systems (i.e. core temperature) and, consequently, the ability of PSI to discriminate physiological strain in response to differing levels of heat stress, or in situations where thermoregulation is impaired. However, as the data generally reported in these studies are on individuals who tolerated the different heat exposures, there is limited evidence supporting the use of PSI to identify individuals at potential risk of HIF or heat-related illnesses, or in other words, reaching a thermal tolerance limit.

Exhaustion or fatigue associated with an elevated $T_{\mathrm{c}}$ (i.e. HIF) is becoming more widely recognised as an event caused by the interplay of both central and peripheral physiological factors, alongside psychological processes such as motivation, previous experience and expectation of demand (Flouris and Schlader 2015; Nybo et al. 2014). The multi-factorial nature of HIF is evidenced by the observation that the $T_{\mathrm{c}}$ at which the onset of HIF occurs is highly individualised (Ely et al. 2009). Other parameters have been associated with HIF, such as cardiovascular strain reflected in HR (Périard et al. 2011), supporting the notion that PSI could be used to identify individuals at risk of HIF. However, to the authors' knowledge this has yet to be explored. Therefore, the aim of this study was to assess whether PSI can identify individuals at risk of HIF and/or heat-related illnesses (i.e. individuals reaching a thermal tolerance limit) in a variety of heat stress scenarios designed to represent conditions experienced in both indoor and outdoor worksites. The chosen heat stress scenarios varied in regard to climatic conditions [i.e. ambient temperature $\left(25-40{ }^{\circ} \mathrm{C}\right)$, relative humidity $(20-85 \%)$, and the presence of simulated solar radiation], the clothing worn (i.e. clothing of different vapour permeability) and the type and length of metabolic activity. 


\section{Methods}

\section{Participants}

Fifteen females and 21 males participated in the study (Females: age $=25.2 \pm 6.7$ years; body mass $=61.3 \pm 5.9 \mathrm{~kg}$; peak oxygen uptake $=47.45 \pm 11.09 \mathrm{ml} \mathrm{kg} \mathrm{m^{-1 }}$; body fat $=20.34 \pm 6.11 \%$, Males: age $=24.8 \pm 5.7$ years; body mass $=76.1 \pm 9.5 \mathrm{~kg}$; peak oxygen uptake $=50.69 \pm 9.34 \mathrm{~m}$

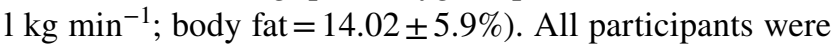
verbally briefed, issued with a participant information sheet, and gave written informed consent. Ethical approval for the procedures was obtained from Loughborough University ethics committee and designed in accordance with the 2013 Declaration of Helsinki regarding human experimentation.

\section{Experimental procedures}

Prior to commencing the main trials, all participants underwent a maximal intensity fitness test on a treadmill to determine peak oxygen uptake $\left(\dot{V} O_{2 \text { peak }}\right)$. Participants were also measured for height, body mass and estimated body fat percentage (Durnin and Womersley 1974). Participants undertook between two and nine trials (each separated by at least 3 days). Trials were completed at the same time of day for each participant (either $8 \mathrm{am}, 12 \mathrm{pm}$ or $4 \mathrm{pm}$ ) to account for circadian rhythm changes in core temperature and cardiovascular responses.

Each trial differed either in ambient temperature and relative humidity (rh), the type of clothing worn (impermeable or permeable), the presence of a radiant heat source $\left(\sim 530 \mathrm{Wm}^{-2}\right.$ focused on the back of the participant) and/or the work/rest regime (see Table 2 and Fig. 1). The rationale behind the wide variation in conditions (work and climate) of the trials was to ensure the results derived would be relevant to the wide variation of conditions encountered in real life work scenarios (e.g. indoor and outdoor), rather than to a single heat/work stress condition. The chosen conditions of the trials were also aimed at participants achieving body core temperatures above $38.5^{\circ} \mathrm{C}$ in all trials.

Each trial started with a 10 -min seated rest period to allow for a stabilisation in skin and rectal temperatures. With the exception of condition 3, trials in conditions 1-9 consisted of completing a work/rest regime that involved two 40- to 60-min periods of walking on a treadmill at an exercise intensity of $\sim 40 \% \dot{V} O_{2 \text { peak }}$ separated by seated rest in $\sim 22{ }^{\circ} \mathrm{C}, 50 \%$ rh outside the climatic chamber. The duration of seated rest was determined by the rate of recovery/ decline in rectal temperature $\left(T_{\mathrm{re}}\right)$ of the individual, with participants returning to the climatic chamber once $T_{\mathrm{re}}$ had dropped by $0.4{ }^{\circ} \mathrm{C}$ (average time $=10-20 \mathrm{~min}$ ).

Condition 3 was designed to simulate a typical work regime of an industrial worker and to evaluate various transitions of metabolic activity and, therefore, heat production. The work/rest regime of trials in this condition involved two 25 -min periods of treadmill walking of varying intensity involving $5 \mathrm{~min}$ of moderate exercise $\left(\sim 35 \% \dot{V} O_{2 \text { peak }}\right), 5 \mathrm{~min}$ of moderate to hard exercise $\left(\sim 65 \% \dot{V} O_{2 \text { peak }}\right)$ and $15 \mathrm{~min}$ of moderate exercise $\left(\sim 35 \% \dot{V} O_{2 \text { peak }}\right)$ separated by $10 \mathrm{~min}$ of seated rest in the climatic chamber. After the completion of the second 25-min period of treadmill walking, the
Fig. 1 Two of the types of protective clothing worn by the participants: a impermeable clothing and $\mathbf{b}$ permeable clothing, plus localised thermal radiation directed onto the back of the participants
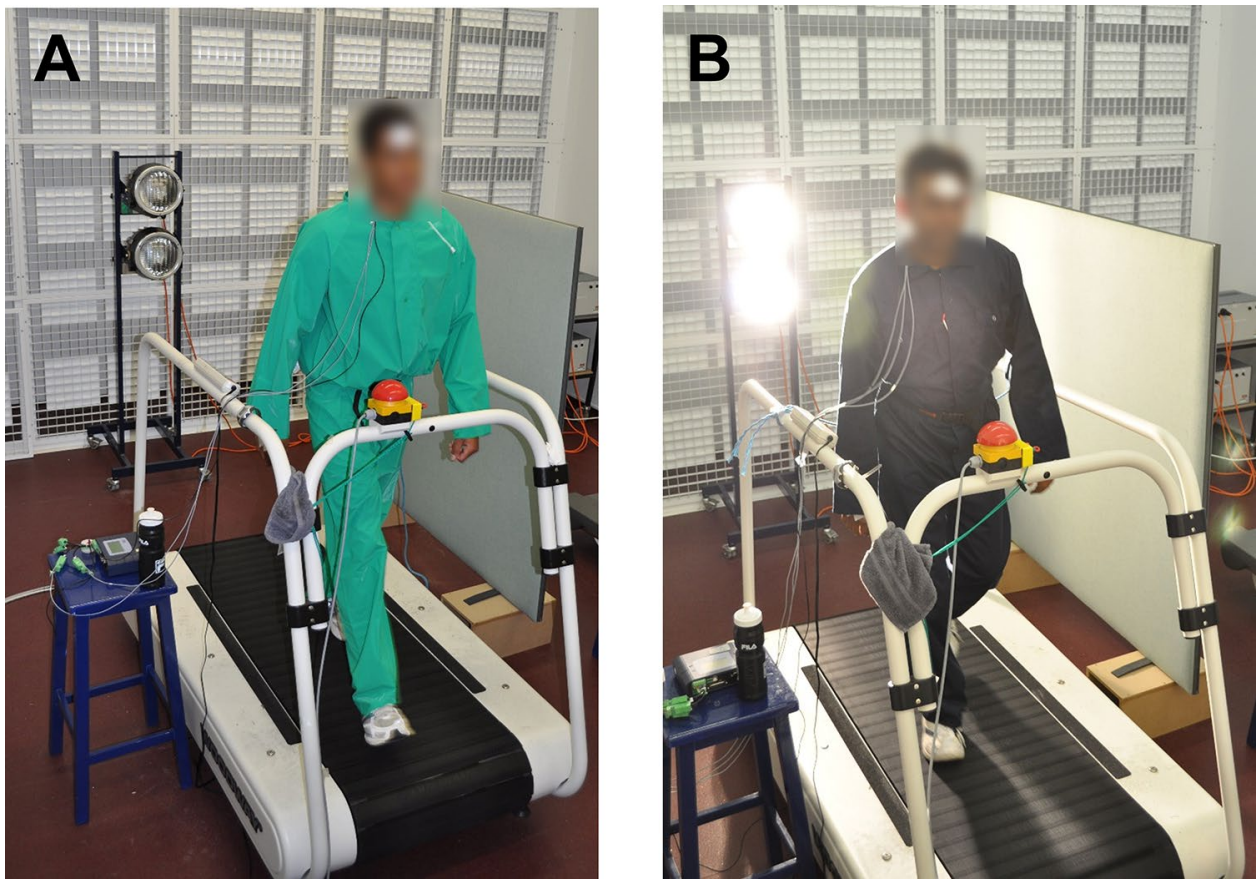
participant rested in $\sim 22{ }^{\circ} \mathrm{C}, 50 \%$ rh outside the climatic chamber (as per conditions 1-9), before completing another 25 -min period of treadmill walking of varying intensity (thus completing a total of $3 \times 25$ min periods of treadmill walking) followed by $10 \mathrm{~min}$ of seated rest in the climatic chamber as part of the same trial. Participants were allowed to drink ad libitum throughout a trial. To reflect a typical working scenario where hydration practices would be encouraged, but not enforced, participants were encouraged to be euhydrated (i.e. urine to be pale yellow in colour) at the beginning of a trial, but hydration status was not measured. To assess the level of hypohydration in participants over a trial the difference between pre and post nude body mass was measured. The amount of fluid consumed and urine volume was also measured to assess sweat rate.

Two 1000 W Metal Halide Compact Source Iodide (CSI) lamps (GE Lighting) were used to simulate solar radiation. These lamps produce light with a spectrum similar to that of sunlight. The radiation was directed from behind the participant and angled to concentrate the radiation onto the posterior torso region. The intensity and direction of the radiation were controlled by the distance $(\sim 2.3 \mathrm{~m})$ and angle of the lamps from the participant walking on the treadmill. The amount of direct radiation was measured with a Pyranometer (CM11, Kipp \& Zonen, Netherlands) prior to and every 10 min during the trial.

The participants wore either a permeable or impermeable two layered clothing system, matched for dry insulation. Each clothing system included a long-sleeved shirt (100\% cotton) and shorts (100\% Lycra) as the first layer, then either the permeable or impermeable all-in-one suits as the second layer, worn with a belt at the waist. The total thermal resistance and evaporative resistance for the permeable clothing system were $0.166 \mathrm{~m}^{2} \mathrm{~K} \mathrm{~W}^{-1}$ and $42.4 \mathrm{~m}^{2} \mathrm{~Pa} \mathrm{~W}^{-1}$ and for the impermeable clothing system $0.167 \mathrm{~m}^{2} \mathrm{~K} \mathrm{~W}^{-1}$ and $213.3 \mathrm{~m}^{2} \mathrm{~Pa} \mathrm{~W}^{-1}$, respectively.

In the present study, a trial could be stopped prematurely either by the researcher or volitionally by the participant. Reasons for terminating the trial included the following: the participant feeling excessively fatigued or exhibiting signs and symptoms of heat-related illnesses, e.g. mental confusion, lack of co-ordination, clammy, pale skin, nausea, dizziness and headache. All researchers were experienced in administering exercise protocols in both thermally challenging and thermoneutral conditions and therefore able to recognise signs and symptoms of heat-related illnesses and HIF. A trial terminated prematurely was assigned to group TTL (thermal tolerance limit) to represent a population who could not complete the heat stress scenario due to HIF and/ or other symptoms of heat-related illnesses. For simplicity the term of thermal tolerance limit will be used hereafter to describe incidences of HIF and/or other symptoms of heatrelated illnesses. Trials that were completed were assigned to group C (Control). To ensure the safety of participants, the following criteria were also used for stopping a trial (1) $T_{\mathrm{re}}>39.5^{\circ} \mathrm{C}$; (2) HR above $95 \%$ of age-predicted maximum. Only 4 trials were ceased prematurely due to the latter safety criteria. As the participants in these trials did not display any signs and symptoms of a heat-related illness or reported feelings of fatigue, the data from these trials were excluded from the analyses. The rationale for this exclusion was the uncertainty to whether the participant would have gone on to complete the trial or stop prematurely due to reaching a thermal tolerance limit.

\section{Measurements}

The following measurements were recorded in all trials: (1) $T_{\text {re }}$ (self-inserted; Edale Instruments, Cambridge, UK); (2) local skin temperature of the forehead $\left(T_{\text {head }}\right)$, chest $\left(T_{\text {chest }}\right)$, upper back $\left(T_{\text {u.back }}\right)$, upper $\operatorname{arm}\left(T_{\text {u.arm }}\right)$, lower $\operatorname{arm}\left(T_{\text {l.arm }}\right)$, hand $\left(T_{\text {hand }}\right)$, lower back $\left(T_{\text {l.back }}\right)$, abdomen $\left(T_{\text {abdominal }}\right)$, thigh $\left(T_{\text {thigh }}\right)$, calf $\left(T_{\text {calf }}\right)$ and foot $\left(T_{\text {foot }}\right)$ were measured on the right-hand side of the body (iButtons thermochrons, Homechip, Milton Keynes, UK) and the average of these temperatures was used to calculate mean skin temperature $\left(T_{\mathrm{sk}}\right)$; (3) HR (RS 800, Polar, Finland). Environmental measurements of ambient temperature, relative humidity, radiant heat and wind speed were also recorded (Testo 453, Testo SE \& Co, Germany). Every five minutes, participants were asked for their subjective rating of thermal comfort (TC) and temperature sensation (TS). Both the TC and TS were recorded on horizontal visual analogue scales ranging from very comfortable to very uncomfortable and very cold to very hot, respectively. The corresponding scores ranged from 0 to 20 with higher scores representing feeling more uncomfortable on the TC scale and feeling hotter on the TS scale (Davey et al. 2007).

\section{Calculations}

\section{Physiological strain index (PSI)}

Several variations to the calculation of PSI were assessed as follows:

(1) PSI $_{\text {original }}$ (Moran et al. 1998a, b): PSI calculated using the actual resting values for $T_{\mathrm{re}}(0)$ and $\mathrm{HR}(0)$ :

$\mathrm{PSI}=5 \times \frac{T_{\mathrm{re}}(t)-T_{\mathrm{re}}(0)}{39.5-T_{\mathrm{re}}(0)}+5 \times \frac{\mathrm{HR}(t)-\mathrm{HR}(0)}{180-\mathrm{HR}(0)}$,

where $T_{\mathrm{re}}(t)=$ current $T_{\mathrm{re}}, T_{\mathrm{re}}(0)=$ initial $T_{\mathrm{re}}, \mathrm{HR}(t)=$ current $\mathrm{HR}$ and $\mathrm{HR}(0)=$ initial HR.

(2) PSI $_{\text {fixed }}$ (Buller et al. 2008): PSI calculated using fixed values for the starting point, i.e. $T_{\text {re }}(0)$ and $\operatorname{HR}(0)$ at $37.0^{\circ} \mathrm{C}$ and 70 beats $\mathrm{min}^{-1}$, respectively. This version 
of the PSI was assessed as, on a practical level, it is not always possible to establish resting values in a thermoneutral environment. The fixed values used are similar to the mean initial $T_{\text {re }}$ and HR values recorded at the beginning of all heat exposures, i.e. $37.17( \pm 0.26){ }^{\circ} \mathrm{C}$ and 76 $( \pm 13)$ beats $\min ^{-1}$ :

$\mathrm{PSI}_{\text {fixed }}=5 \times \frac{T_{\mathrm{re}}(t)-37.0}{39.5-37.0}+5 \times \frac{\mathrm{HR}(t)-70}{180-70}$

(3) The adaptive-PSI (aPSI) (Buller et al. 2016) was also assessed as it has been shown to better identify levels of heat strain than the PSI $I_{\text {fixed }}$ (Buller et al. 2016). The aPSI adjusts the critical core temperature of $39.5^{\circ} \mathrm{C}$ used in PSI fixed by the gradient between $T_{\mathrm{c}}$ and $T_{\mathrm{sk}}$ as follows:

$\mathrm{PSI}=5 \times \frac{T_{\mathrm{re}}(t)-T_{\mathrm{re}}(0)}{39.5+\frac{\left[T_{\mathrm{re}}(t)-T_{\mathrm{sk}}(t)\right]-4}{4}-T_{\mathrm{re}}(0)}+5 \times \frac{\mathrm{HR}(t)-\mathrm{HR}(0)}{180-\mathrm{HR}(0)}$

(4) Finally, to determine whether incorporating skin temperature in the form of heat storage into the PSI equation would provide a better prediction of an individual reaching a thermal tolerance limit, the following modification to the calculation of PSI was also evaluated:

$\mathrm{PSI}_{\mathrm{HS}}=5 \times \frac{\mathrm{HS}(t)}{\mathrm{HS}_{\text {crit }}-\mathrm{HS}(0)}+5 \times \frac{\mathrm{HR}(t)-\mathrm{HR}(0)}{180-\mathrm{HR}(0)}$,

where $\operatorname{HS}(t)=\left(0.8 \bullet\left[T_{\mathrm{re}}(t)-T_{\mathrm{re}}(0)\right]\right)+(0.2 \bullet$ $\left.\left[T_{\mathrm{sk}}(t)-T_{\mathrm{sk}}(0)\right]\right) \bullet 3.49\left(\mathrm{~J} \mathrm{~g}^{-1}\right)$; Havenith et al. (1995), $\mathrm{HS}_{\text {crit }}=(0.8 \bullet[39.5-37.0])+(0.2 \bullet[37.5-32.5]) \bullet$ $\left(\mathrm{J} \mathrm{g}^{-1}\right) ; \mathrm{HS}(0)=0$.

\section{Rate of change in PSI, $T_{\mathrm{sk}}, \mathrm{HR}$ and $T_{\text {re }}$}

As group TTL experienced shorter heat exposures than group C (see "Results" section) it is plausible that they would have reached a certain PSI earlier than group $\mathrm{C}$ so, as a consequence, the rate of change (ROC) in $\mathrm{PSI}_{\text {fixed }}$ was also calculated using the following equation:

ROC in PSI fixed $=\frac{\text { Final PSI }}{\text { fixed }_{\text {Initial PSI }}-\text { Inixed }}$

Across a trial the ROC in $T_{\mathrm{re}}, T_{\mathrm{sk}}, T_{\mathrm{re}}-T_{\mathrm{sk}}$ and HR were calculated in the same manner as ROC PSI fixed The ROC in the last ten minutes of a trial was also calculated (i.e. $T_{\text {re } 10}, T_{\text {sk10 }}, \mathrm{HR}_{10}, T_{\text {re10 }}-T_{\text {sk10 }}$ and $\left.\mathrm{PSI}_{\text {fixed } 10}\right)$. The latter parameters were included as they were considered to be more pragmatic to incorporate into a heat strain index/ heat stress monitor as generally the length of exposure before reaching a thermal tolerance limit is generally unknown, especially on an individual basis.

\section{Statistical analysis}

All data are presented as means \pm standard deviation (SD) unless stated otherwise. Cumulative frequency graphs were

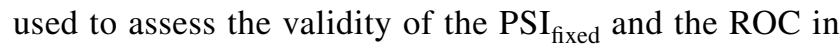
PSI $_{\text {fixed }}$ to identify individuals at risk of reaching a thermal tolerance limit. To determine whether PSI can identify individuals reaching a TTL, regardless of the type of heat stress scenario i.e. condition, independent $t$-tests (or where variables were not normally distributed the Mann-Whitney $U$ test) were used to compare variables recorded at the end of a trial between groups TTL and C. These measures included final PSI original $_{1}$, PSI $_{\text {fixed }}$, aPSI, PSI $I_{\mathrm{HS}}, \mathrm{HR}, T_{\mathrm{re}}, T_{\mathrm{sk}}, T_{\mathrm{re}}-T_{\mathrm{sk}}$, TS, TC, $\Delta \mathrm{HR}, \Delta T_{\mathrm{re}}, \Delta T_{\mathrm{sk}}, \Delta T_{\mathrm{re}}, \mathrm{ROC}$ in $\mathrm{PSI}_{\text {fixed }}, T_{\mathrm{re}}$, $T_{\mathrm{sk}}, \mathrm{HR}, T_{\mathrm{re}}-T_{\mathrm{sk}}$ (both over a trial and in the last $10 \mathrm{~min}$ of a trial). To determine whether there was a condition effect, only the conditions that produced the most cases of individuals reaching a TTL (i.e. conditions, 1, 2 and 6), were used to perform a two-way independent measures ANOVA to assess the interaction of group and condition on PSI $_{\text {fixed }}$ and

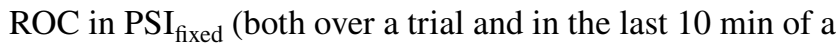
trial). The ANOVA was only performed using the 3 conditions listed due to the variance in the number of participants undertaking and the number of participants reaching TTL in the other conditions (Table 4). When a significant difference was found for a main effect (group or condition), post-hoc pair-wise comparisons were made incorporating a Bonferroni adjustment. Effect sizes for pairwise comparisons were calculated using either corrected Cohen's $d$ (i.e. hedges's $g$; Cumming 2012) for independent $t$-tests or the conversion of $z$ scores to $r$ values for Mann-Whitney $U$ tests (Field, 2013). Commonly used interpretations of cohen's $d$ and $r$ vales is to refer effect sizes as small $(d \geq 0.2, r=0.1-0.3)$, medium $(d \geq 0.5, r=0.3-0.5)$ and large $(d \geq 0.8, r=0.5-1.0)$ (Cohen 1988). All statistical procedures were performed using the Statistical Package for the Social Sciences 24.0 for Windows (SPSS, Inc., Chicago, IL, USA). Statistical significance was set at $p<0.05$.

\section{Results}

Out of 150 trials, 115 trials (74.8\%) were completed and 35 trials (22.7\%) were stopped prematurely due to the participant reaching a thermal tolerance limit. Every participant who participated in condition 7 completed the trial; therefore, this condition was removed from the analyses. However, a description of this condition and corresponding PSI values have been included in Tables 2, 4, to provide an example of a heat stress scenario where individuals reaching a thermal tolerance limit is less likely to occur, or, in other words, a heat stress scenario tolerated by the majority and therefore maybe deemed less of a health and 
safety risk. Consequently, the 101 trials that were completed comprised group $\mathrm{C}$ and the 35 trials being stopped prematurely comprised group TTL.

The average length of heat exposure for group TTL was $87.74 \pm 29.26 \mathrm{~min}$ (range $35-125 \mathrm{~min}$ ) and $118.31 \pm 9.14 \mathrm{~min}$ (range 100-145 min) for group C. Table 1 demonstrates that the physical characteristics of participants were similar between groups TTL and C. Most cases of TTL occurred in conditions 1, 2 and 6; conditions that generally had the highest ambient water vapour pressure or included impermeable clothing, both of which would have induced a higher water vapour at the skin surface compromising evaporative heat loss (see Tables 2, 4). The majority of participants completed at least $80 \%$ of their trials (median $=80 \%$ ) with only two participants unable to complete any of the trials attempted (no of trials attempted $=2-3$ ). In all trials attempted, these two participants ceased exercising due to experiencing either fatigue, dizziness or a headache. These two participants' final $T_{\text {re }}$ and HR ranged between 38.0 and $38.7{ }^{\circ} \mathrm{C}$ and $130-150$ beats $\min ^{-1}$, respectively which could be considered moderate thermal strain. Across all conditions the \% change in nude body mass was $-0.42 \pm 0.81 \%$. This level of hypohydration experienced during the trials is equivalent to those likely experienced in workplaces where participants have access to fluids and are educated on the importance of hydration (Brearley et al. 2015).

Due to technical issues, $T_{\mathrm{sk}}$ was not obtained at the end of one trial in group TTL, and HR was not obtained for two trials in group $\mathrm{C}$ and one trial in group TTL. Therefore the $\mathrm{n}$ sizes for $\mathrm{PSI}_{\text {original }}, \mathrm{PSI}_{\text {fixed }}$, aPSI, were 99 (C group) and 34 (TTL group) and for PSI $_{\mathrm{HS}} 101$ (C group) and 34 (TTL group). In the subjective measures (TC and TS), the n sizes were 93 (C group) and 28 (TTL group).

Table 1 Physical characteristics of the participants in groups $\mathrm{C}$ and TTL; mean \pm SD $(n=36)$

\begin{tabular}{|c|c|c|}
\hline Physical characteristics & $C$ & TTL \\
\hline$N$ & 13 & 23 \\
\hline Age (years) & $25.8 \pm 7.1$ & $25.3 \pm 5.5$ \\
\hline Body mass (kg) & $69.7 \pm 12.5$ & $70.9 \pm 10.0$ \\
\hline Body surface area $\left(\mathrm{m}^{2}\right)$ & $1.84 \pm 0.21$ & $1.85 \pm 0.16$ \\
\hline Body fat $(\%)$ & $14.66 \pm 7.49$ & $17.50 \pm 7.23$ \\
\hline Peak oxygen uptake $\left(\mathrm{ml} \mathrm{kg} \min ^{-1}\right)$ & $52.42 \pm 9.90$ & $47.26 \pm 10.15$ \\
\hline
\end{tabular}

None of the variables were significantly different between groups. $\mathrm{TTL}=$ Group comprised of participants who stopped a trial prematurely at least once due to hyperthermia-induced fatigue or another heat-related symptom (i.e. reached a thermal tolerance limit), $C=$ Group comprised of participants who completed all the trials they attempted

\section{Physiological parameters}

Final $T_{\mathrm{re}}, \mathrm{HR}$ and the $\Delta$ in $T_{\mathrm{re}}$ were not significantly different between TTL and C. However, there was a significant difference between TTL and C in: final $T_{\mathrm{sk}} ; T_{\mathrm{re}}-T_{\mathrm{sk}} ; \Delta T_{\mathrm{sk}} ; \mathrm{ROC}$ in $T_{\mathrm{re}} ; \mathrm{ROC}$ in $T_{\mathrm{sk}}$ and ROC in HR; Table 3 . The ROC in the last 10 min of a trial was greater in group TTL than group $\mathrm{C}$ in the following measures: ROC $T_{\text {re } 10}$; ROC $T_{\text {sk } 10}$; ROC $\mathrm{HR}_{10}$; ROC $T_{\text {re10 }}-T_{\text {sk10 }}$; Table 3 . There were no significant differences in the other physiological parameters measured.

\section{Physiological strain index}

All versions of the PSI assessed (i.e. $\mathrm{PSI}_{\text {fixed }}, \mathrm{PSI}_{\mathrm{HS}}$, aPSI) were strongly correlated with $\mathrm{PSI}_{\text {original }}(r=0.869-0.964$, $p<0.01)$. Across all conditions, none of the versions of the PSI assessed in the present study differed between TTL and C; Table 3. Due to this outcome, results using PSI $\mathrm{fixed}_{\text {will }}$ only be described hereafter.

PSI $_{\text {fixed }}$ differed across conditions 1,2 and 6 ( $F$ $\left.(2,44)=4.28, p=0.020 ; \eta p^{2}=0.163\right)$. There was no main effect in $\mathrm{PSI}_{\text {fixed }}$ for group $(F(1,44)=2.55, p=0.117$; $\left.\eta p^{2}=0.055\right)$ or an interaction between group and condition $\left(F(2,44)=1.55, p=0.233 ; \eta p^{2}=0.066\right)$. However, PSI fixed $_{\text {}}$ differed significantly between TTL and $\mathrm{C}$ in condition 2

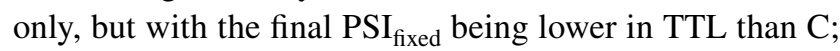
Table 4.

Across all conditions, the ROC in $\mathrm{PSI}_{\text {fixed }}$ calculated over a trial and over the last 10 min was significantly greater in TTL than C; Table 3. For the ROC in PSI fixed $_{\text {calculated }}$ over a trial the main effect of condition was significant ( $F$ $\left.(2,44)=9.82, p<0.001 ; \eta p^{2}=0.309\right)$ as was the main effect for group $\left(F(1,44)=9.65, p=0.003 ; \eta p^{2}=0.309\right)$, but not for an interaction between group and condition $(F(2,44)=2.37$, $\left.p=0.105 ; \eta p^{2}=0.097\right)$. Within conditions 1,2 and 6 , the

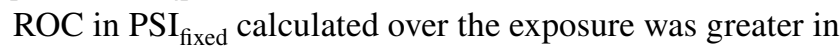
TTL than $C$ in condition 6 only (TTL $=0.12 \pm 0.05 \mathrm{~min}^{-1}$ vs. $C=0.07 \pm 0.01 \mathrm{~min}^{-1}, p=0.001, d=1.15$ ).

The ROC in $\mathrm{PSI}_{\text {fixed }}$ over the last 10 min $\left(\mathrm{ROC}_{\text {fixed10 }}\right)$ showed a main effect of condition $(F(2,44)=12.15$, $\left.p<0.001 ; \eta p^{2}=0.361\right)$, but there was no main effect for group $\left(F(1,44)=0.82, p=0.771 ; \eta p^{2}=0.002\right)$ nor an interaction between group and condition $(F(2,44)=0.25$, $p=0.771 ; \eta p^{2}=0.012$ ).

Figure 2 is a cumulative frequency graph displaying the

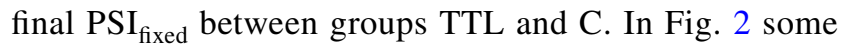
of the PSI fixed values are over 10 because HR was higher than the estimated maximum HR $\left(180\right.$ beats $\left.\mathrm{min}^{-1}\right)$ included

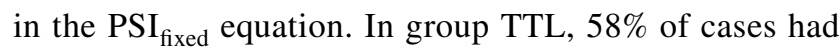
a PSI $<7.5$. In addition, $29.4 \%$ did not reach a PSI fixed over 6 (the 'high' PSI zone) when they stopped prematurely due to reaching a thermal tolerance limit. The grey dashed lines show the $\mathrm{PSI}_{\text {fixed }}$ when $50 \%$ of the individuals 


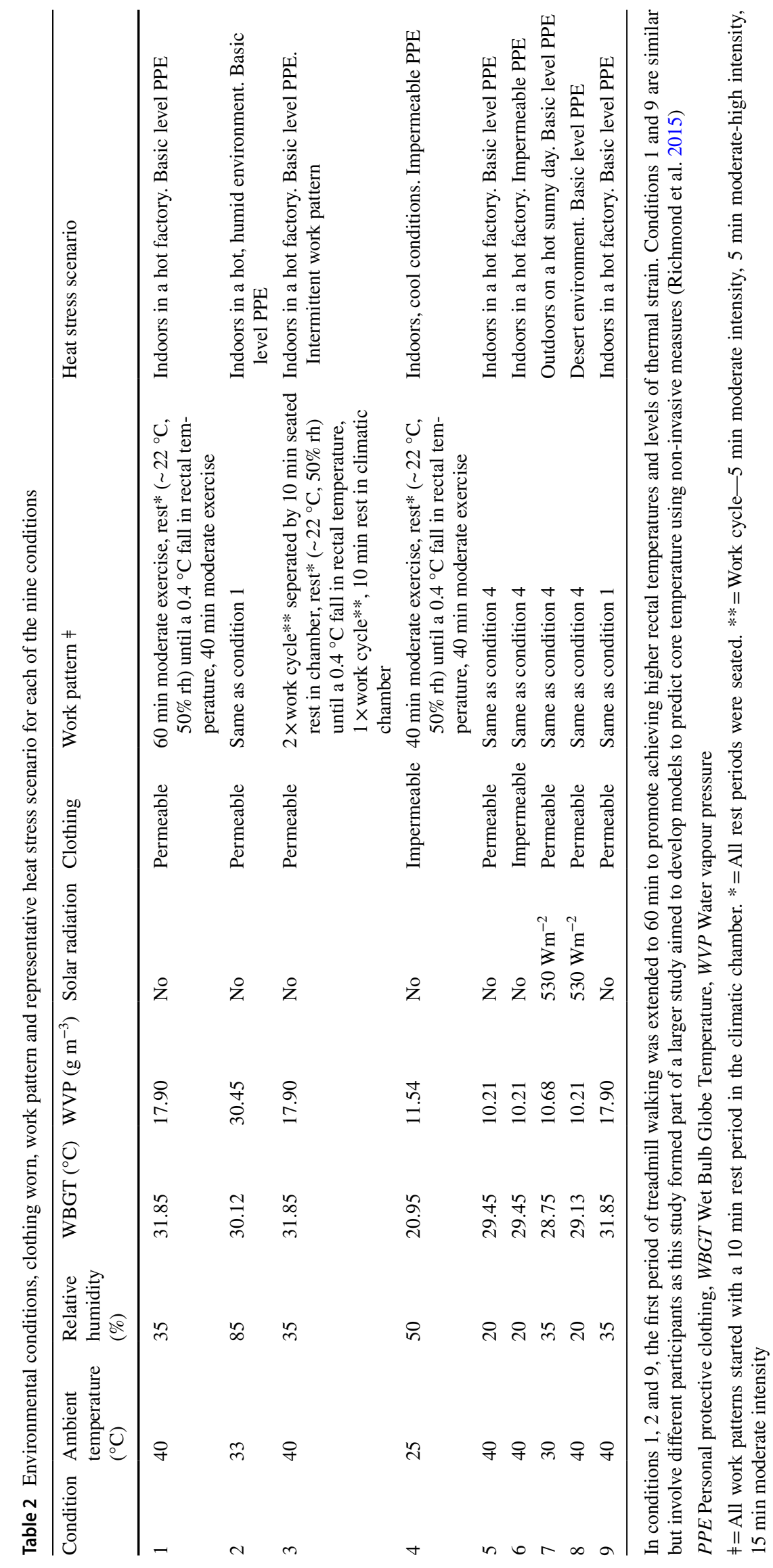


Table 3 Mean \pm SD of selected measured variables from the participants who completed the trials (Group C) versus those who experienced reaching a thermal tolerance limit (Group TTL)

\begin{tabular}{|c|c|c|c|c|c|}
\hline & $C$ & TTL & $p$ value & Effect size $(d)$ & Effect size $(r)$ \\
\hline \multicolumn{6}{|l|}{ Physiological variables } \\
\hline Final $T_{\text {re }}\left({ }^{\circ} \mathrm{C}\right)$ & $38.57 \pm 0.40$ & $38.57 \pm 0.44$ & $>0.05$ & - & - \\
\hline Final $T_{\mathrm{sk}}\left({ }^{\circ} \mathrm{C}\right)$ & $37.34 \pm 0.88$ & $37.77 \pm 0.81$ & 0.014 & 0.50 & - \\
\hline Final HR (beats $\min ^{-1}$ ) & $150 \pm 20$ & $157 \pm 18$ & $>0.05$ & - & - \\
\hline Final $T_{\mathrm{re}}-T_{\mathrm{sk}}\left({ }^{\circ} \mathrm{C}\right)$ & $1.29 \pm 0.67$ & $0.80 \pm 0.80$ & 0.022 & 0.60 & - \\
\hline$\Delta$ in $T_{\text {re }}\left({ }^{\circ} \mathrm{C}\right)$ & $1.49 \pm 0.50$ & $1.46 \pm 0.54$ & $>0.05$ & - & - \\
\hline$\Delta$ in $T_{\mathrm{sk}}\left({ }^{\circ} \mathrm{C}\right)$ & $4.99 \pm 1.14$ & $5.44 \pm 1.03$ & 0.034 & 0.42 & - \\
\hline $\mathrm{ROC}$ in $T_{\mathrm{re}}\left({ }^{\circ} \mathrm{C} \cdot \mathrm{min}^{-1}\right)$ & $0.013 \pm 0.004$ & $0.019 \pm 0.010$ & $<0.001$ & - & 0.27 \\
\hline $\mathrm{ROC}$ in $T_{\mathrm{sk}}\left({ }^{\circ} \mathrm{C} \cdot \mathrm{min}^{-1}\right)$ & $0.043 \pm 0.010$ & $0.073 \pm 0.039$ & $<0.001$ & - & 0.45 \\
\hline ROC in HR (beats $\min ^{-1}$ ) & $0.66 \pm 0.21$ & $0.98 \pm 0.49$ & $<0.001$ & - & 0.31 \\
\hline $\mathrm{ROC}$ in $T_{\mathrm{re} 10}\left({ }^{\circ} \mathrm{C} \cdot \mathrm{min}^{-1}\right)$ & $0.022 \pm 0.009$ & $0.032 \pm 0.018$ & $<0.001$ & - & 0.32 \\
\hline $\mathrm{ROC}$ in $T_{\mathrm{sk} 10}\left({ }^{\circ} \mathrm{C} \cdot \mathrm{min}^{-1}\right)$ & $0.019 \pm 0.015$ & $0.036 \pm 0.022$ & 0.001 & - & 0.47 \\
\hline $\mathrm{ROC}$ in $\mathrm{HR}_{10}$ (beats $\mathrm{min}^{-1}$ ) & $0.42 \pm 0.54$ & $0.82 \pm 0.82$ & 0.001 & - & 0.32 \\
\hline $\mathrm{ROC}$ in $T_{\mathrm{re}}-T_{\mathrm{sk} 10}\left({ }^{\circ} \mathrm{C} \cdot \mathrm{min}^{-1}\right)$ & $0.003 \pm 0.010$ & $0.004 \pm 0.016$ & 0.015 & - & 0.22 \\
\hline \multicolumn{6}{|l|}{ Physiological strain indices } \\
\hline $\mathrm{PSI}_{\text {fixed }}$ & $6.8 \pm 1.5$ & $7.1 \pm 1.5$ & $>0.05$ & - & - \\
\hline PSI $_{\text {original }}$ & $6.6 \pm 1.6$ & $6.7 \pm 1.9$ & $>0.05$ & - & - \\
\hline aPSI & $7.6 \pm 2.1$ & $8.3 \pm 2.2$ & $>0.05$ & - & - \\
\hline $\mathrm{PSI}_{\mathrm{HS}}$ & $7.9 \pm 1.4$ & $8.4 \pm 1.3$ & $>0.05$ & - & - \\
\hline $\mathrm{ROC}$ in $\mathrm{PSI}_{\text {fixed }}\left(\mathrm{min}^{-1}\right)$ & $0.06 \pm 0.01$ & $0.09 \pm 0.04$ & $<0.001$ & - & 0.45 \\
\hline $\mathrm{ROC}$ in $\mathrm{PSI}_{\text {fixed } 10}\left(\mathrm{~min}^{-1}\right)$ & $0.06 \pm 0.03$ & $0.10 \pm 0.05$ & $<0.001$ & - & 0.37 \\
\hline \multicolumn{6}{|l|}{ Thermal perceptions } \\
\hline Final temperature sensation & $17.7 \pm 1.9$ & $18.8 \pm 1.3$ & 0.006 & - & 0.25 \\
\hline Final thermal comfort & $16.3 \pm 3.6$ & $18.3 \pm 2.0$ & 0.005 & - & 0.27 \\
\hline
\end{tabular}

Commonly used interpretations of cohen's $d$ and $r$ vales is to refer effect sizes as small $(d \geq 0.2, r=0.1-$ $0.3)$, medium $(d \geq 0.5, r=0.3-0.5)$ and large $(d \geq 0.8, r=0.5-1.0)$ (Cohen 1988)

$T_{r e}$ rectal temperature, $T_{s k}$ skin temperature, $H R$ heart rate, $P S I_{\text {fixed }}$ physiological strain index calculated from fixed resting values i.e. $37.0{ }^{\circ} \mathrm{C}$ and 70 beats $\mathrm{min}^{-1}, P S I_{\text {original }}$ physiological strain index calculated from actual resting values, $a P S I$ the adaptive physiological strain index, $P S I_{H S}$ physiological strain index calculated from an estimate of heat storage, $R O C$ rate of change stopped prematurely $\left(\mathrm{PSI}_{\text {fixed }}=7.3\right)$ or completed a trial $\left(\mathrm{PSI}_{\text {fixed }}=6.7\right)$. Figure 2 demonstrates that to protect $95 \%$ of individuals from reaching a thermal tolerance limit in the TTL group, they would need to stop at a PSI $_{\text {fixed }}$ value of 4.8. However, a termination criteria of a PSI $_{\text {fixed }}$ of 4.8 would result in $91.0 \%$ of the trials being stopped prematurely in group $\mathrm{C}$, which otherwise would have been completed safely. Figure 2 also shows the wide inter- and intra-individual vari-

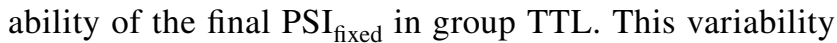
illustrates that there is no clear PSI $_{\text {fixed }}$ value (or range of $\mathrm{PSI}_{\text {fixed }}$ values) that distinguishes the two groups (i.e. group TTL and group C) or is associated with reaching a thermal tolerance limit within an individual. For example, participant 2 reaches a thermal tolerance limit at a PSI $_{\text {fixed }}$ value of 7.2 in one condition, but reaches a thermal tolerance limit at a $\mathrm{PSI}_{\text {fixed }}$ value of 5.3 in another condition.

Figure 3 illustrates that if ROC in $\mathrm{PSI}_{\text {fixed }}$ is used instead, to protect $95 \%$ of individuals from reaching a thermal tolerance limit in the TTL group, they would need to stop when their ROC in $\mathrm{PSI}_{\text {fixed }}$ exceeds a value of $0.05 \mathrm{~min}^{-1}$. This would result in $79.0 \%$ of the trials being stopped prematurely in the $\mathrm{C}$ group which otherwise would have been successfully completed. In addition, $29.4 \%$ of the participants in group TTL had a ROC in PSI fixed above $0.09 \mathrm{~min}^{-1}$, which is the highest value obtained in the $\mathrm{C}$ group.

\section{Perceptual parameters.}

There was a significant difference between TTL and C in both TS and TC; Table 3.

\section{Discussion}

Based on previous literature it was recognised that PSI has the potential to identify individuals at risk of HIF and/or other heat-related symptoms (Buller et al. 2008). In the present study, participants reaching a thermal tolerance limit started to occur around a PSI $_{\text {fixed }}$ value of 4.5 , above which the occurrence increased almost linearly with PSI $_{\text {fixed }}$ before 
Table 4 Physiological strain index ( $\mathrm{PSI}_{\text {fixed }}$ ) values of participants who completed the trials (Group C) versus those who reached a thermal tolerance limit (Group TTL) for each of the nine conditions, mean $\pm \mathrm{SD}$ (range)

\begin{tabular}{|c|c|c|c|c|}
\hline \multirow[t]{2}{*}{ Condition } & \multicolumn{2}{|l|}{$C$} & \multicolumn{2}{|c|}{ TTL } \\
\hline & $n$ & $\mathrm{PSI}_{\text {fixed }}$ & $n$ & PSI $_{\text {fixed }}$ \\
\hline 1 & 11 & $6.8 \pm 1.7(3.9-9.4)$ & 6 & $6.9 \pm 1.8(4.4-8.8)$ \\
\hline 2 & 10 & $7.4 \pm 0.9(6.3-9.0)$ & 7 & $6.1 \pm 0.8(5.3-7.7)^{*}$ \\
\hline 3 & $16^{\dagger}$ & $5.1 \pm 1.4(2.7-6.6)$ & 1 & 5.2 \\
\hline 4 & 14 & $6.1 \pm 1.0(4.9-7.9)$ & 1 & 10.5 \\
\hline 5 & $19^{\dagger}$ & $6.5 \pm 1.4(4.7-9.8)$ & 1 & 4.7 \\
\hline 6 & 7 & $8.3 \pm 0.9(7.3-9.5)$ & $11^{\dagger}$ & $7.6 \pm 0.9(5.8-8.8)$ \\
\hline 7 & 14 & $6.2 \pm 1.3$ & 0 & - \\
\hline 8 & 15 & $\begin{array}{l}7.7 \pm 1.0(6.1- \\
10.1)\end{array}$ & 4 & $7.7 \pm 2.0(6.0-10.1)$ \\
\hline 9 & 9 & $7.8 \pm 1.0(6.1-9.0)$ & 4 & $7.0 \pm 1.1(6.0-8.0)$ \\
\hline $\begin{array}{l}\text { All conditions } \\
\text { (excl. condi- } \\
\text { tion 7) }\end{array}$ & 99 & $\begin{array}{l}6.8 \pm 1.5(2.7- \\
10.1)^{*}\end{array}$ & 34 & $7.1 \pm 1.5(4.4-10.5)$ \\
\hline
\end{tabular}

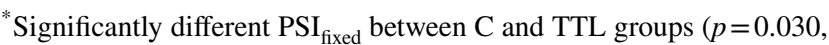
$d=1.58$ ). The $n$ sizes displayed are the actual number of participants who completed or did not complete a trial. Due to no incidences of thermal intolerance occurring in condition 7 , this condition was not included in the final analyses. ${ }^{\dagger}$ Due to technical issues, $T_{\text {sk }}$ was not obtained at the end of one trial in group TTL, and HR was not obtained for two trials in group $\mathrm{C}$ and one trial in group TTL. Therefore, in all conditions (excluding condition 7 ) the $\mathrm{n}$ sizes for the final

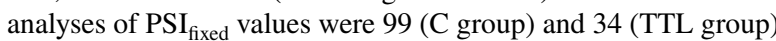

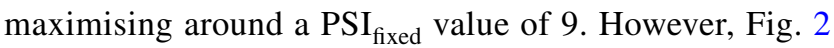
clearly illustrates that PSI $_{\text {fixed }}$ does not discriminate between participants who were able to complete an exercise bout in thermally stressful conditions versus those who were unable to due to reaching a thermal tolerance limit. Moreover, in condition 2, opposite to the expectation, the mean PSI ${ }_{\text {fixed }}$ value was lower in the TTL group than group $\mathrm{C}$, reinforcing the inability of PSI fixed to identify individuals at risk of reaching a thermal tolerance limit. Furthermore, bearing in mind that according to Buller et al. (2008) and Moran et al. (1998b) a PSI value above 7.5 is considered 'at risk' from thermal injury, 58\% of the TTL group experienced HIF or other symptoms of heat-related illnesses causing them to stop exercising before reaching this suggested 'at risk' limit value and $29.4 \%$ did not even reach a PSI $_{\text {fixed }}$ value of 6 (considered the 'high' PSI zone). This highlights that if a value of 6 on the PSI $\mathrm{Pixed}_{\text {f }}$ was used to identify people at risk of reaching a thermal tolerance limit, $\sim 29 \%$ of the heat exposures where participants reached a thermal tolerance limit would not have been detected on time, posing a health and safety risk. The results from this study indicate that to protect $95 \%$ of the population from HIF or a heat-related illness, a PSI ${ }_{\text {fixed }}$ of 4.8 could be used, but this may be considered too conservative as it could result in stopping the majority of workers $(\sim 91 \%)$ successfully completing certain physical tasks. To overcome this problem, it has been identified that monitoring the rate of change in PSI $_{\text {fixed }}$ may be more appropriate to identify individuals at risk of reaching a thermal tolerance limit, rather than utilising an absolute PSI $_{\text {fixed }}$ value. The use of other physiological and perceptual measures such as skin temperature or temperature sensation may also be beneficial.

As aforementioned, the notion of a 'critical' core temperature has been shown to be less predictive of HIF than
Fig. 2 Cumulative frequency showing \% of participants dropping out at each Physiological Strain Index (PSI fixed $_{\text {in }}$ ) value for group TTL and group C. The grey dashed line shows the PSI fixed $_{\text {value when } 50 \%}$ of participants dropped out or completed the trial. The black dashed line represents Buller's (2008) 'at risk' classification of 7.5. The black solid line represents the threshold in $\mathrm{PSI}_{\text {fixed }}$ required to protect $95 \%$ of the TTL group. The numbers associated to the cases in group TTL is the participant identifier corresponding to that case

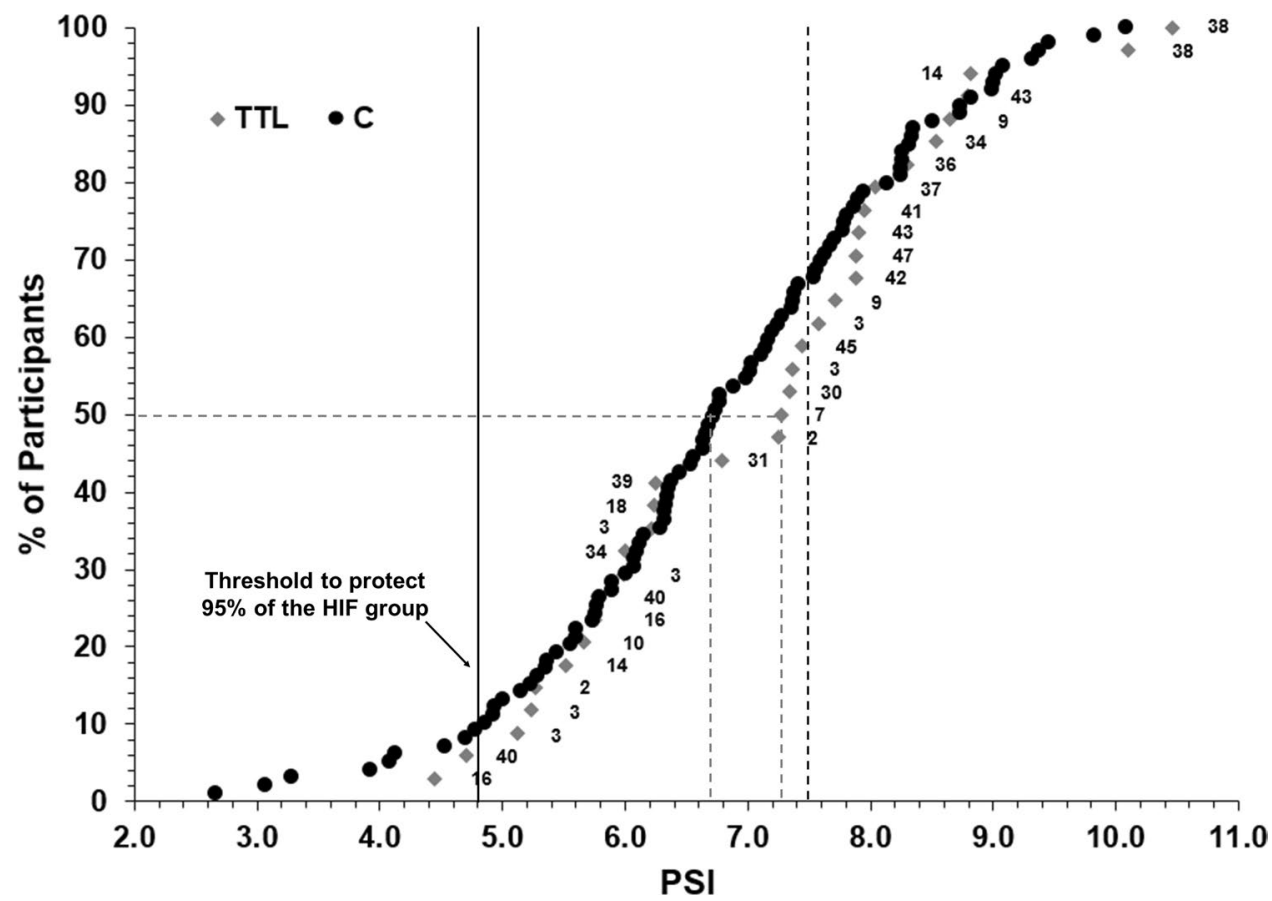


Fig. 3 Cumulative frequency showing $\%$ of participants dropping out at each rate of change (ROC) in the Physiological Strain Index ( $\left.\mathrm{PSI}_{\text {fixed }}\right)$ for group TTL and group C. The grey dashed line shows the ROC in PSI $_{\text {fixed }}$ when 50\% of participants dropped out or completed the trial. The black dashed line represents the upper limit in ROC in $\mathrm{PSI}_{\text {fixed }}$ to complete a trial. The black solid line represents the threshold in $\mathrm{PSI}_{\text {fixed }}$ required to protect $95 \%$ of the TTL group. The numbers associated to the cases in group TTL is the participant identifier corresponding to that case

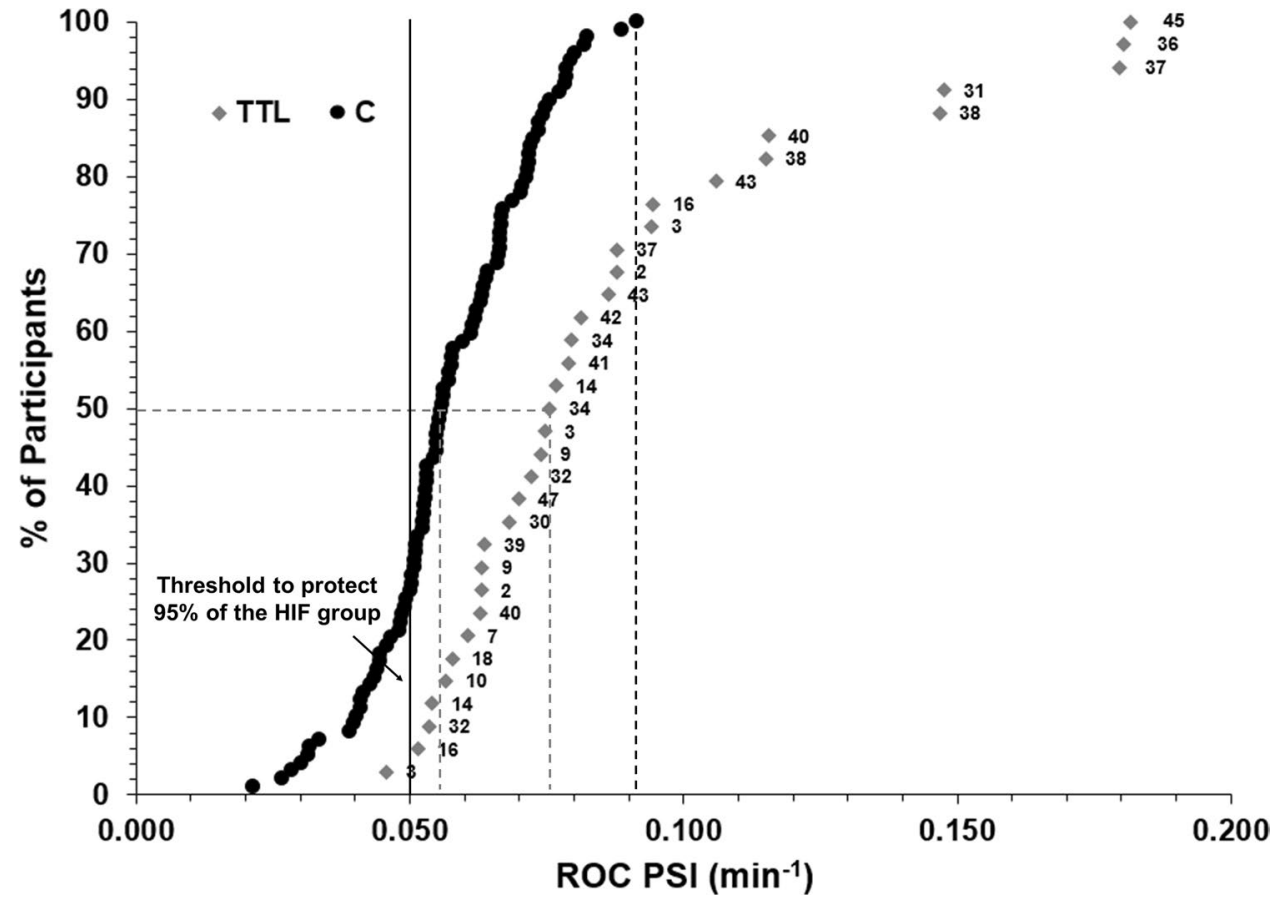

other factors, such as heart rate, skin temperature and the gradient between $T_{\mathrm{c}}$ and $T_{\text {sk }}$ (Cuddy et al. 2014; Ely et al. 2009; Pandolf and Goldman 1978; Périard et al. 2011; Schlader et al. 2011). The present study provides further evidence with final $T_{\text {re }}$ being similar between the two groups (i.e. $\sim 38.5^{\circ} \mathrm{C}$ ). In addition, similarily to previous observations (Montain et al. 1994), some participants in the present study reached a thermal tolerance limit at a far lower $T_{\text {re }}$ than 'critical' core temperatures of $39.0-40.0^{\circ} \mathrm{C}$, i.e. $37.9-38.0^{\circ} \mathrm{C}$. This may explain why the $\mathrm{PSI}_{\text {fixed }}$ equation underestimated the physiological strain experienced in the majority of cases in the TTL group as the PSI $\mathrm{Pixed}_{\text {fix }}$ includes an assumed 'critical' core temperature of $39.5^{\circ} \mathrm{C}$. This observation supports the incorporation of a core temperature of $38.0^{\circ} \mathrm{C}$ as a good safety margin in many occupational heat stress guidelines to protect the majority of the population of developing a heat-related illness (ACGIH, 2009; ISO 7933 2004). However, as previously highlighted, a core temperature limit of $38.0{ }^{\circ} \mathrm{C}$ may be considered too conservative in certain scenarios mainly due to core temperatures associated with thermal tolerance being influenced by several factors such as aerobic training, acclimation status, hydration status, exercise intensity, clothing and environmental parameters (e.g. hot-dry vs hot-wet environments) (Cheung and McLellan 1998; Montain et al. 1999; Stewart et al. 2014). The present study suggests that monitoring the rate of change in core temperature over a set period, such as ten minutes, may provide a better predictor of reaching of a thermal tolerance limit than a specific absolute core temperature.
The present study provides further evidence that a higher skin temperature and the smaller gradient between $T_{\mathrm{c}}$ and $T_{\mathrm{sk}}$ is associated with a thermal tolerance limit as both parameters were different between groups TTL and $\mathrm{C}$ at the end of a trial (i.e. a difference of $\sim 0.43{ }^{\circ} \mathrm{C}$ in $T_{\text {sk }}$ and $\sim 0.49{ }^{\circ} \mathrm{C}$ in the gradient between $T_{\mathrm{c}}$ and $T_{\mathrm{sk}}$ ). Several studies have identified skin temperature as a modulator for exercise intensity (Schlader et al. 2011; Schulze et al. 2015) and ratings of perceived exertion (RPE) (Armada-da-Silva et al. 2004) whilst exercising in the heat. In addition, when encapsulating/impermeable PPE is worn, reduced work tolerance times generally correspond with lower core temperatures and higher skin temperatures compared to when non-encapsulating/permeable PPE is worn (McLellan and Havenith 2016; Montain et al. 1994; Stewart et al. 2014). This evidence suggests incorporating skin temperature into heat strain indices/ heat stress monitors may improve the validity of identifying individuals at risk of reaching a thermal tolerance limit in a wide range of thermally stressful conditions.

To provide more accurate reflections of physiological strain in scenarios where HIF may occur at core temperatures below $39.5^{\circ} \mathrm{C}$, Buller et al. (2016) developed the adaptive PSI (aPSI). As previously described, the aPSI adjusts the critical core temperature of $39.5^{\circ} \mathrm{C}$ used in the original PSI by the gradient between $T_{\mathrm{c}}$ and $T_{\mathrm{sk}}$. Even though this modified version has been demonstrated to better identify levels of heat strain than the original PSI (Buller et al. 2016), with larger $T_{\mathrm{c}}-T_{\mathrm{sk}}$ gradients resulting in a lower PSI, the present study demonstrates that it is unable to identify individuals reaching a thermal tolerance limit in a wide range 
of thermally stressful conditions and therefore caution must be adopted when utilised in thermally stressful occupations.

Even though absolute $T_{\text {re }}$ was not found to be associated with reaching a thermal intolerance limit, the rate of heat storage (reflected in the ROC in $T_{\text {re }}$ and $T_{\text {sk }}$ ) was different between TTL and C over a whole trial and in the last 10 min of a trial. The rate at which heat is stored within the body has previously been shown to cause an alteration in exercise intensity (Tucker et al. 2006) possibly due to the anticipatory regulation of exercise intensity which is eloquently described in Marino, 2004 and Tatterson et al. 2000. This may explain why the rate of change in $\mathrm{PSI}_{\text {fixed }}$ observed in the current study was different between TTL and C, but

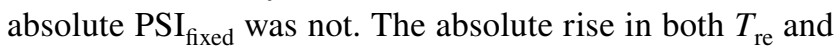
HR did not differ between the two groups, i.e. $\sim 1.45^{\circ} \mathrm{C}$ and 77 beats $\min ^{-1}$, respectively, but the rate of change in $T_{\mathrm{re}}$ and HR were both different. In the study by Tucker et al. (2006) the difference in the rate of rise in heat storage between the condition that caused a greater reduction in exercise intensity was mainly driven by the rate of change in mean skin temperature. This observation reinforces the importance of skin temperature as a determinant of TTL and may explain why all the parameters associated with skin temperature, i.e. final $T_{\mathrm{sk}}, \mathrm{ROC}$ in $T_{\mathrm{sk}}$ and $T_{\mathrm{sk} 10}$ and the absolute change in $T_{\mathrm{sk}}$, did discriminate between the two groups. However, when skin temperature in the form of heat storage is incorporated into the PSI equation (i.e. PSI $_{\mathrm{HS}}$ ), it does not sufficiently improve its ability to identify individuals reaching a thermal tolerance limit.

Temperature sensation and thermal comfort have also been highlighted as key regulators of exercise intensity, especially at lower levels of hyperthermia (Flouris and Schlader 2015). To increase the practicality of indices that estimate physiological strain, heat strain indices using only perceptual measures have been developed (Borg et al. 2017; Gallagher et al. 2012; Tikuisis et al. 2002). For example, Tikuisis et al. (2002) developed a perception-based version of the PSI, (i.e. PeSI), replacing heart rate and core temperature with temperature sensation and RPE and using the upper limits of the perceptual scales $(13=$ intolerably hot and $10=$ maximal exertion) as critical values. The perception-based heat strain index was validated against the PSI to assess physiological strain in aerobically trained and untrained participants performing open-ended moderate exercise in a hot-dry environment $\left(40{ }^{\circ} \mathrm{C}, 30 \% \mathrm{rh}\right)$ while wearing semipermeable protective clothing. The untrained participants ceased exercise sooner than the trained participants (69 vs $95 \mathrm{~min}$ ) with a lower mean core temperature $\left(38.58^{\circ} \mathrm{C}\right.$ vs $39.21^{\circ} \mathrm{C}$ ) and PSI value (6.7 vs. 8.2), but with a similar mean heart rate $\left(\sim 163\right.$ beats $\left.\mathrm{min}^{-1}\right)$. However, both groups ceased exercise with a similar rating of PeSI ( 6.5) suggesting that PeSI is a better predictor of an individual's TTL than PSI. In the present study, the participants in the
TTL group reported feeling hotter and more uncomfortable compared to participants who completed a trial, even though core temperature was similar between the two groups. However, the difference in skin temperature observed between the two groups might be driving this difference in thermal perception. Unfortunately, RPE was not measured in all trials in the present study, therefore, we were unable to assess the ability of PeSI to identify risk of reaching a thermal tolerance limit.

In regard to both validity and practicality, perceptualbased indices similar to the PeSI may be more appropriate to use than PSI to identify individuals at risk of reaching a thermal tolerance limit. However, as highlighted in Tikuisis et al. (2002), in some individuals who are highly motivated, or aerobically trained, there is the potential for them to underestimate their physiological strain which places them at risk of a thermal injury such as heat exhaustion or heat stroke. The inclusion of a physiological parameter into a perceptual-based index may counteract this. The results from the present and previous studies, such as Cuddy et al. (2013), suggest that the inclusion of skin temperature or heart rate, especially the rate of change in these two measures, may offer a plausible solution. In both solutions, including a rate of change of a physiological parameter over the previous ten minutes, rather than over a whole exposure, would provide a better depiction of the thermal state of the individual. This is important as work scenarios tend to involve metabolic activity that is intermittent in nature and can last several hours.

Due to the multi-factorial nature of HIF, it could be considered understandable that including a combination of perceptual/physiological and psychological parameters would increase the probability of correctly identifying individuals at risk of reaching a thermal tolerance limit. However, one drawback of increasing the number of parameters included in a heat strain index/heat stress monitor is the risk of reducing their usability in work-place settings as they may become impractical and/or too expensive. In regard to producing an index that protects the majority of people without compromising productivity, another difficulty for all proposed indices will be establishing the critical threshold in any parameters used. Thresholds are likely to be highly individualised and influenced by the interplay between changes in skin temperature and core temperature and their effect on the cardiovascular, respiratory and central nervous systems.

\section{Limitations}

While the data collected for this study provide strong evidence regarding the limited utility of PSI as a protective index, they unfortunately do not allow a more detailed analysis of threshold limit values. If all participants had exercised to exhaustion (or voluntary cessation) in all conditions, it 
would be easier to identify specific thresholds conducive for individuals reaching a thermal tolerance limit in the physiological and perceptual parameters measured. However, such an experiment series would have been extremely stressful for participants and repeating such exhaustive trials many times may have been difficult to do reliably and safely.

\section{Conclusion}

In summary, the findings from the present study suggest that the absolute PSI is not a valid measure to identify workers at risk from HIF and/or other heat related symptoms associated with a thermal tolerance limit and caution should be taken if utilised within thermally stressful occupations. This is the case for all variations of PSI considered: PSI $_{\text {original }}$, PSI $_{\text {fixed }}$, aPSI and PSI $\mathrm{HS}_{\mathrm{HS}}$. Similarly absolute $T_{\mathrm{re}}$ or HR were not predictive of reaching a thermal tolerance limit. However, there is potential for the rate of change in PSI or a physiologicalperceptual strain index that incorporates a combination of either a rate of change in $T_{\mathrm{re}}, T_{\mathrm{sk}}$ or HR with thermal perceptions to be a more valid measure. Further investigations are required to validate these suggested changes to PSI.

Acknowledgements The authors would like to thank the participants who volunteered their time to partake in this study.

Author contributions The study was designed by GH, SD, VD and KG; data were collected by SD, VD and KG; Data was analysed by SD, data interpretation and manuscript preparation were undertaken by SD, KG and GH. GH obtained the project funding. All authors approved the final version of the paper.

Funding This work was supported by European Commission for project funding FP7-NMP-2008SME-2, Proj. No. 229042: PROSPIE-Protective Responsive Outer Shell for People in Industrial Environments.

\section{Compliance with ethical standards}

Conflict of interest The authors declare that the research was conducted in the absence of any commercial or financial relationships that could be construed as a potential conflict of interest.

Open Access This article is licensed under a Creative Commons Attribution 4.0 International License, which permits use, sharing, adaptation, distribution and reproduction in any medium or format, as long as you give appropriate credit to the original author(s) and the source, provide a link to the Creative Commons licence, and indicate if changes were made. The images or other third party material in this article are included in the article's Creative Commons licence, unless indicated otherwise in a credit line to the material. If material is not included in the article's Creative Commons licence and your intended use is not permitted by statutory regulation or exceeds the permitted use, you will need to obtain permission directly from the copyright holder. To view a copy of this licence, visit http://creativecommons.org/licenses/by/4.0/.

\section{References}

ACGIH (2009) TLVs® and BEI®s. Threshold limit values for chemical substances and physical agents. Biological exposures indices. In: American conference of governmental industrial hygienists, Cincinnati

Arbury S, Jacklitsch B, Farquah O et al (2014) Heat illness and death among workers-United States, 2012-2013. MMWR Morb Mortal Wkly Rep 63:661-665 (PMID: 25102413)

Armada-da-Silva PAS, Woods J, Jones DA (2004) The effect of passive heating and face cooling on perceived exertion during exercise in the heat. Eur J Appl Physiol 91:563-571. https://doi.org/10.1007/ s00421-007-0652-z

Borg D, Costello J, Bach A, Stewart I (2017) Perceived exertion is as effective as the perceptual strain index in predicting physiological strain when wearing personal protective clothing. Physiol Behav 169:216-223. https://doi.org/10.1016/j.physb eh.2016.12.009

Brearley M, Harrington P, Lee D, Taylor R (2015) Working in hot conditions-a study of electrical utility workers in the northern territory of Australia. J Occup Environ Hyg 12(3):156-162. https://doi.org/10.1080/15459624.2014.957831

Buller M, Latzka W, Yokota M, Tharion W, Moran D (2008) A real-time heat strain risk classifier using heart rate and skin temperature. Physiol Meas 29:N79-85. https://doi. org/10.1088/0967-3334/29/12/N01

Buller M, Looney D, Welles A, Ely B, Tharion W, Hoyt R (2016) An adaptive physiological strain index that accounts for thermal-work strain in high-performance athletes and encapsulated workers. In: International conference on the physiology and pharmacology of temperature regulation, Slovenia

Cheung SS, McLellan TM (1998) Heat acclimation, aerobic fitness and hydration effects on tolerance during uncompensable heat stress. J Appl Physiol 84:1731-1739. https://doi.org/10.1152/ jappl.1998.84.5.1731

Cohen J (1988) Statistical power analysis for the behavioral sciences. Routledge Academic, New York

Cuddy JS, Buller M, Hailes WS, Ruby BC (2013) Skin temperature and heart rate can be used to estimate physiological strain during exercise in the heat in a cohort of fit and unfit males. Mil Med 178(7):e841-e847. https://doi.org/10.7205/MILME D-D-12-00524

Cuddy J, Walter H, Ruby B (2014) A reduced core to skin temperature gradient, not a critical core temperature, affects aerobic capacity in the heat. J Therm Biol 43:7-12. https://doi.org/10.1016/j.jther bio.2014.04.002

Cumming G (2012) Understanding the new statistics: effect sizes, confidence intervals, and meta-analysis. Routledge, New York

Davey S, Reilly T, Newton M, Tipton M (2007) The reproducibility and validity of visual analogue scales (VAS) that assess thermal perceptions in stable and dynamic, asymmetric environments. In: Proceedings of the 12th international conference of environmental ergonomics, Piran, Slovenia, 19-24 August 2007

Durnin JV, Womersley J (1974) Body fat assessed from total body density and its estimation from skinfold thickness: measurements on 481 men and women aged from 16 to 72 years. Br J Nutr 32:77-97. https://doi.org/10.1079/bjn19740060

Ely B, Ely M, Cheuvront S, Kebefick RW, DeGroot D, Montain S (2009) Evidence against a $40{ }^{\circ} \mathrm{C}$ core temperature threshold for fatigue in humans. J Appl Physiol 107:1519-1525. https://doi. org/10.1152/japplphysiol.00577.2009

Field A (2013) Discovering statistics using IBM SPSS statistics, 4th edn. Sage Publications Ltd. ISBN: 978-1-4462-4918-5. 
Flouris AD, Schlader ZJ (2015) Human behavioral thermoregulation during exercise in the heat. Scand J Med Sci Sport 25:52-64. https ://doi.org/10.1111/sms.12349

Flouris AD, Dinas P, Ioannou L, Nybo L, Havenith G, Kenny G, Kjellstrom T (2018) Workers' health and productivity under occupational heat strain: a systematic review and meta-analysis. Lancet Planet Health 2(12):e521-e531. https://doi.org/10.1016/S2542 $-5296(18) 30237-7$

Foster J, Smallcombe J, Hodder S, Jay O, Flouris A, Havenith G (2019) A new paradigm to quantify the reduction of physical work capacity in the heat. Med Sci Sports Exerc 51(6):15-15

Gallagher M, Robertson RJ, Goss FL, Nagle-Stilley EF, Schafer MA, Suyama J, Hostler D (2012) Development of a perceptual hyperthermia index to evaluate heat strain during treadmill exercise. Eur J Appl Physiol 112:2025-2034. https://doi.org/10.1007/s0042 1-011-2173-z

Havenith G, Fiala D (2015) Thermal indices and thermophysiological modeling for heat stress. Comp Physiol 6(1):255-302. https://doi. org/10.1002/cphy.c140051

Havenith G, Luttikholt VG, Vrijkotte TG (1995) The relative influence of body characteristics on humid heat stress response. Eur J Appl Physiol 70(3):270-279. https://doi.org/10.1007/BF00238575

ILO (2016) UNDP. Climate change and labour: impacts of heat in the workplace. ILO Publ, Geneva

ISO (2004). ISO 7933:2004. Ergonomics of the thermal environment-analytical determination and interpretation of heat stress using calculation of predicted heat strain. International Standards Organisation, Geneva

Jendritzky G, de Dear R, Havenith G (2012) UTCI-Why another thermal index? Int J Biometeorol 56(3):421-428. https://doi. org/10.1007/s00484-011-0513-7

Malchaire J, Piette A, Kampmann B, Mehnert P, Gebhardt HJ, Havenith G, Den Hartog E, Holmer I, Parsons K, Alfano G, Griefahn B (2001) Development and validation of the predicted heat strain model. Ann Occup Hyg 45(2):123-135 (PMID: 11182426)

Marino F (2004) Anticipatory regulation and avoidance of catastrophe during exercise-induced hyperthermia. Comp Biochem Physiol B Biochem Mol Biol 139:561-569. https://doi.org/10.1016/j. cbpc.2004.09.010

McLellan TM, Havenith G (2016) Protective clothing ensembles and physical employment standards. Appl Physiol Nutr Metab 41(6):S121-S130. https://doi.org/10.1139/apnm-2015-0474

Montain SJ, Sawka MN, Cadarette BS, Quigley MD, McKay JM (1994) Physiological tolerance to uncompensable heat stress: effects of exercise intensity, protective clothing, and climate. J Appl Physiol 77(1):216-222. https://doi.org/10.1152/jappl.1994.77.1.216

Moran DS (2000) Stress evaluation by the physiological strain index (PSI). J Basic Clin Physiol Pharmacol 11:403-423. https://doi. org/10.1152/ajpregu.1999.276.6.R1798

Moran D, Montain S, Pandolf K (1998a) Evaluation of different levels of hydration using a new physiological strain index. Am J Physiol 275:R854-860. https://doi.org/10.1152/ajpregu.1998.275.3.R854

Moran D, Shitzer A, Pandolf K (1998b) A physiological strain index to evaluate heat stress. Am J Physiol 275:R129-134. https://doi. org/10.1152/ajpregu.1998.275.1.R129

Moran D, Shapiro Y, Laor A, Izraeli S, Pandolf K (1999) Can gender differences during exercise-heat stress be assessed by the physiological strain index? Am J Physiol 276:R1798-1804. https://doi. org/10.1152/ajpregu.1999.276.6.R1798

National Institute for Occupational Safety and Health (NIOSH) (2016) Criteria for a recommended standard: Occupational exposure to heat and hot environments. In: Jacklitsch B, Williams W, Musolin K, Turner N, Coca A, Kim J-H (eds) U.S. Department of Health and Human Services, Centers for Disease Control and Prevention, National Institute for Occupational Safety and Health, Cincinnati

Nybo L, Rasmussen P, Sawka MN (2014) Performance in the heat: physiological factors of importance for hyperthermia-induced fatigue. Comp Physiol 4(2):657-689. https://doi.org/10.1002/ cphy.c130012

Pandolf KB, Goldman RF (1978) Convergence of skin and rectal temperatures as a criterion for heat tolerance. Aviat Space Environ Med 49:1095-1101 (PMID: 697673)

Périard JP, Cramer M, Chapman P, Caillaud C, Thompson M (2011) Cardiovascular strain impairs prolonged self-paced exercise in the heat. Exp Physiol 96(2):134-144. https://doi.org/10.1113/expph ysiol.2010.054213

Petruzzello SJ, Gapin JI, Snook E, Smith DL (2009) Perceptual and physiological heat strain: examination in firefighters in laboratory- and field-based studies. Ergonomics 52:747-754. https:// doi.org/10.1080/00140130802550216

Richmond VL, Davey S, Griggs K, Havenith G (2015) Prediction of core body temperature from multiple variables. Ann Occup Hyg 59(9):1168-1178. https://doi.org/10.1093/annhyg/mev054

Schlader ZJ, Simmons SE, Stannard SR, Mündel T (2011) Skin temperature as a thermal controller of exercise intensity. Eur J Appl Physiol 111:1631-1639. https://doi.org/10.1007/s00421-010-1791-1

Schulte P, Bhattacharya A, Butler C, Chun H, Jacklitsch B, Jacobs T, Kiefer M, Lincoln J, Pendergrass S, Shire J, Watson J, Wagner G (2016) Advancing the framework for considering the effects of climate change on worker safety and health. J Occup Environ Hyg 13(11):847-865. https://doi.org/10.1080/15459624.2016.1179388

Schulze E, Daanen H, Levels K, Casadio J, Plews D, Kiling A, Siegel R, Laursen P (2015) Effect of thermal state and thermal comfort on cycling performance in the heat. Int J Sports Physiol Performance 10(5):655-663. https://doi.org/10.1123/ijspp.2014-0281

Seppänen O, Fisk WJ (2005) Control of temperature for health and productivity in offices. ASHRAE Trans 111:680-686 (Report Number: LBNL-55448)

Stewart IB, Stewart KL, Worringham CJ, Costello JT (2014) Physiological tolerance times while wearing explosive ordnance disposal protective clothing in simulated environmental extremes. PLoS ONE 9(2):e83740. https://doi.org/10.1371/journal.pone.0083740

Tatterson AJ, Hahn AG, Martini DT, Febbraio MA (2000) Effects of heat stress on physiological responses and exercise performance in elite cyclists. J Sci Med Sport 3:186-193. https://doi.org/10.1016/ S1440-2440(00)80080-8

Tikuisis P, McLellan TM, Selkirk G (2002) Perceptual versus physiological heat strain during exercise-heat stress. Med Sci Sports Exerc 34:1454-1461. https://doi.org/10.1016/s1440 -2440(00)80080-8

Tucker R, Marle T, Lambert E, Noakes T (2006) The rate of heat storage mediates an anticipatory reduction in exercise intensity during cycling at a fixed rating of perceived exertion. J Physiol 574:905915. https://doi.org/10.1113/jphysiol.2005.101733

Publisher's Note Springer Nature remains neutral with regard to jurisdictional claims in published maps and institutional affiliations. 